\title{
Establishment of reference range for thyroid hormones (T3, T4 \& TSH) in adult female population at clinical biochemistry laboratory of GCS medical college \& hospital- A descriptive study
}

\author{
Prashant M Jadav ${ }^{1, *}$, Ramesh Pradhan ${ }^{2}$ \\ ${ }^{\mathbf{1}}$ Assistant Professor, ${ }^{2}$ Professor, Dept. of Biochemistry, GCS Medical College Hospital \& Research Centre, Ahmedabad, \\ Gujarat, India
}

*Corresponding Author:

Email: drprashantjadav86@yahoo.com

Received: $26^{\text {th }}$ October, 2017

Accepted: $15^{\text {th }}$ December, 2017

\begin{abstract}
Aim: To establish reference range of T3, T4 and TSH of adult female population at Clinical Biochemistry Laboratory GCS Hospital, Ahmedabad.

Materials and Methods: The study was conducted among 151 healthy females who had undergone health check up at GCS hospital. Blood samples were collected for a period from June, 2015 to October, 2016. The mean age of all the females was 42.49 and the median was 42.00 years, with ages ranging from 23 to 70 years. Participants who had diabetes, hypertension, history of drug intake or any other systemic disease were not included in the study.

Results: Established reference ranges are $0.77-1.69 \mathrm{ng} / \mathrm{ml}, 5.37-12.10 \mu \mathrm{g} / \mathrm{dl}$ and $0.50-5.06 \mu \mathrm{IU} / \mathrm{ml}$ for T3, T4 and TSH hormones respectively.

Conclusion: The thyroid hormone reference interval of the study considerably varies from that of manufacturer's range. There should be need for population based specific range for clinical laboratories running at tertiary hospitals.
\end{abstract}

Keywords: Reference range.

\section{Introduction}

Thyroid hormone disorders have become a major problem around the world in recent times. The number of thyroid patients has been continuously increasing. Normal reference range is always a question in the patients of thyroid disorder. Thyroid function tests, routinely used in clinical practice to diagnose thyroid disorders, are known to be influenced by age, ethnicity, geographical and climatic conditions, and other biological variables including nutrition and lifestyle. ${ }^{1,2}$ In 2002, the National Health and Nutrition Examination Survey (NHANES) III, suggested that $95 \%$ of the US disease-free population had a serum TSH concentration between 0.45 and $4.12 \mathrm{mIU} / \mathrm{L} .{ }^{3,4}$ The International federation of clinical chemistry recommends that each laboratory should establish its own reference range. However, the selection of healthy reference subjects and the determination of reference values are timeconsuming processes. Therefore, many laboratories use reference ranges obtained from the scientific literature or provided by the manufacturer. ${ }^{5}$ This study aims to establish local reference ranges for thyroid function tests among the patients attending GCS Hospitals.

\section{Materials and Methods}

The study was conducted at clinical Biochemistry laboratory, GCS Hospital, Ahmedabad. Total 151 healthy female volunteers were included. Written and informed consent was taken. The study was reviewed and approved by ethical committee of GCSMCH \& RC.
Blood samples were collected using Vacutainer gel separator tubes and left to clot for $30 \mathrm{~min}$ at room temperature before centrifugation at $3000 \mathrm{rpm}$ for 15 min. Sample were analyzed for T3, T4 and TSH on Cobas e411 instrument of Roche company using chemiluminescence method. Those subjects who are suffering from diabetes, hypertension or any systemic disorder, those on medications interfering in results were not included in study. Screening for normal kidney and liver function was done by assaying serum creatinine and SGPT respectively. Data for T3, T4 and TSH were summarized by calculating the mean, standard deviation and ranges for each parameter. T4, T3 and TSH were tested by similar methods in apparently healthy cohorts of adult populations. ${ }^{6}$ The NCCLS guidelines for determination of reference ranges were followed. ${ }^{7}$

The normality of the Variables or the goodness of fit of the distributions of T3, T4 and TSH were calculated by using one sample Kolmogorov-Smirnov test. Normal distribution (position of cumulative probabilities) was used to calculate reference limits. For this analysis, both approaches were used depending on the properties of distribution. The Dixon and Block procedures were used to identify outliers. ${ }^{8,9}$

Confidence intervals were calculated according to binomial distribution. ${ }^{10}$

\section{Statistical Analysis}

Data was analyzed using Statistical Package for Social Sciences (SPSS) Version 20.0. Variables: Mean, 
median, mode, standard deviation, variance, geometric mean, coefficient of skewness, coefficient of kurtosis, range, minimum, maximum, percentiles were calculated using descriptive statistics (Table 1). Pearson's Correlation analysis was used to study the correlation of T3 and T4 with TSH (Table 3).

Table 1: Descriptive analysis of thyroid function tests

\begin{tabular}{|c|c|c|c|c|c|}
\hline & & Age & T3 & T4 & TSH \\
\hline \multicolumn{2}{|c|}{ Sample Size } & 151 & 151 & 151 & 151 \\
\hline \multicolumn{2}{|c|}{ Mean } & 42.4967 & 1.2313 & 8.7789 & 2.7809 \\
\hline \multicolumn{2}{|c|}{ Std. Error of Mean } & .65931 & .01856 & .13838 & .09314 \\
\hline \multicolumn{2}{|c|}{ Median } & 42.0000 & 1.2000 & 8.6000 & 2.7000 \\
\hline \multicolumn{2}{|c|}{ Mode } & 40.00 & 1.10 & $7.50^{\mathrm{a}}$ & 3.00 \\
\hline \multicolumn{2}{|c|}{ Std. Deviation } & 8.10175 & .22807 & 1.70050 & 1.14449 \\
\hline \multicolumn{2}{|c|}{ Variance } & 65.638 & .052 & 2.892 & 1.310 \\
\hline \multicolumn{2}{|c|}{ Geometric Mean } & 41.71505129 & 1.2103548 & 8.618858714 & 2.539186118 \\
\hline \multicolumn{2}{|c|}{ P-value } & 0.318 & 0.000 & 0.000 & 0.000 \\
\hline \multicolumn{2}{|c|}{$\begin{array}{l}\text { Type of test used for } \\
\text { significance of normality }\end{array}$} & $\begin{array}{l}\text { Kolmogorov } \\
\text { Smirnov Test }\end{array}$ & $\begin{array}{l}\text { Kolmogorov } \\
\text { Smirnov Test }\end{array}$ & $\begin{array}{l}\text { Kolmogorov } \\
\text { Smirnov Test }\end{array}$ & $\begin{array}{l}\text { Kolmogorov } \\
\text { Smirnov Test }\end{array}$ \\
\hline \multicolumn{2}{|c|}{$\begin{array}{l}\text { Significance of normal } \\
\text { distribution }\end{array}$} & non-parametric & Parametric & Parametric & parametric \\
\hline \multicolumn{2}{|c|}{ Coefficient of Skewness } & .204 & .357 & .482 & .472 \\
\hline \multicolumn{2}{|c|}{ Std. Error of Skewness } & .197 & .197 & .197 & .197 \\
\hline \multicolumn{2}{|c|}{ Coefficient of Kurtosis } & .097 & .009 & -.133 & -.341 \\
\hline \multicolumn{2}{|c|}{ Std. Error of Kurtosis } & .392 & .392 & .392 & .392 \\
\hline \multicolumn{2}{|c|}{ Range } & 47.00 & 1.30 & 8.15 & 5.11 \\
\hline \multicolumn{2}{|l|}{ Minimum } & 23.00 & .66 & 4.93 & .79 \\
\hline \multicolumn{2}{|l|}{ Maximum } & 70.00 & 1.96 & 13.08 & 5.90 \\
\hline \multicolumn{2}{|l|}{ Sum } & 6417.00 & 185.92 & 1325.62 & 419.92 \\
\hline \multirow[t]{3}{*}{ Percentiles } & 25 & 36.0000 & 1.1000 & 7.5000 & 1.8300 \\
\hline & 50 & 42.0000 & 1.2000 & 8.6000 & 2.7000 \\
\hline & 75 & 49.0000 & 1.4000 & 9.7000 & 3.4000 \\
\hline
\end{tabular}

Table 2: Confidence intervals of thyroid function tests

\begin{tabular}{|l|c|c|}
\hline \multirow{2}{*}{ Variables } & \multicolumn{2}{|c|}{$\mathbf{9 5 \%}$ Confidence Interval of the Difference } \\
\cline { 2 - 3 } & Lower & Upper \\
\hline T3 & 1.1946 & 1.2679 \\
\hline T4 & 8.5055 & 9.0524 \\
\hline TSH & 2.5969 & 2.9650 \\
\hline
\end{tabular}

Table 3: Pearson's correlation of T3 and T4 with TSH

\begin{tabular}{|l|c|c|}
\hline \multicolumn{3}{|c|}{ Correlation } \\
\hline \multicolumn{1}{|c|}{ Variable 1 } & Variable 2 & r \\
\hline T3 & TSH & -0.037690 \\
\hline T4 & TSH & -0.152020 \\
\hline
\end{tabular}

Results

The $95^{\text {th }}$ and $5^{\text {th }}$ percentile values of upper and lower reference limits of T3, T4 and TSH together with the $95 \%$ confidence intervals are shown in Table 2.

Applying Pearson's Correlation for T3 and T4 with TSH using IBM SPSS version 20.0 the computed ' $r$ ' values are -0.03769 (Fig. 1) and -0.15202 (Fig. 2) respectively which shows that the correlation $\mathrm{T} 3$ and $\mathrm{T} 4$ with TSH is negative. As the Coefficient of Skewness is between -.5 and +0.5 , the distribution is fairly symmetric. 


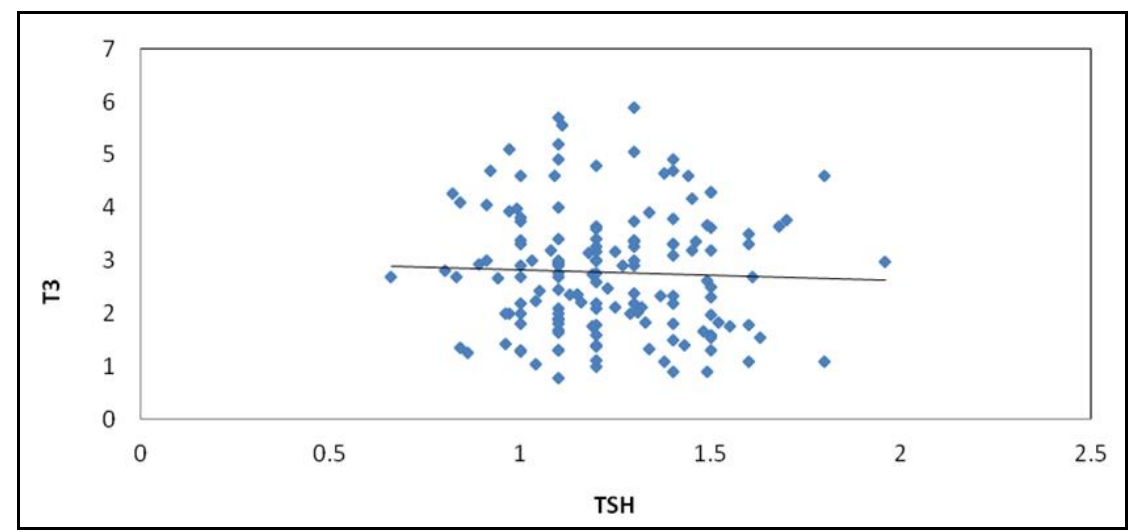

Fig. 1: Scatter Plot between T3 and TSH

\section{Graph 1}
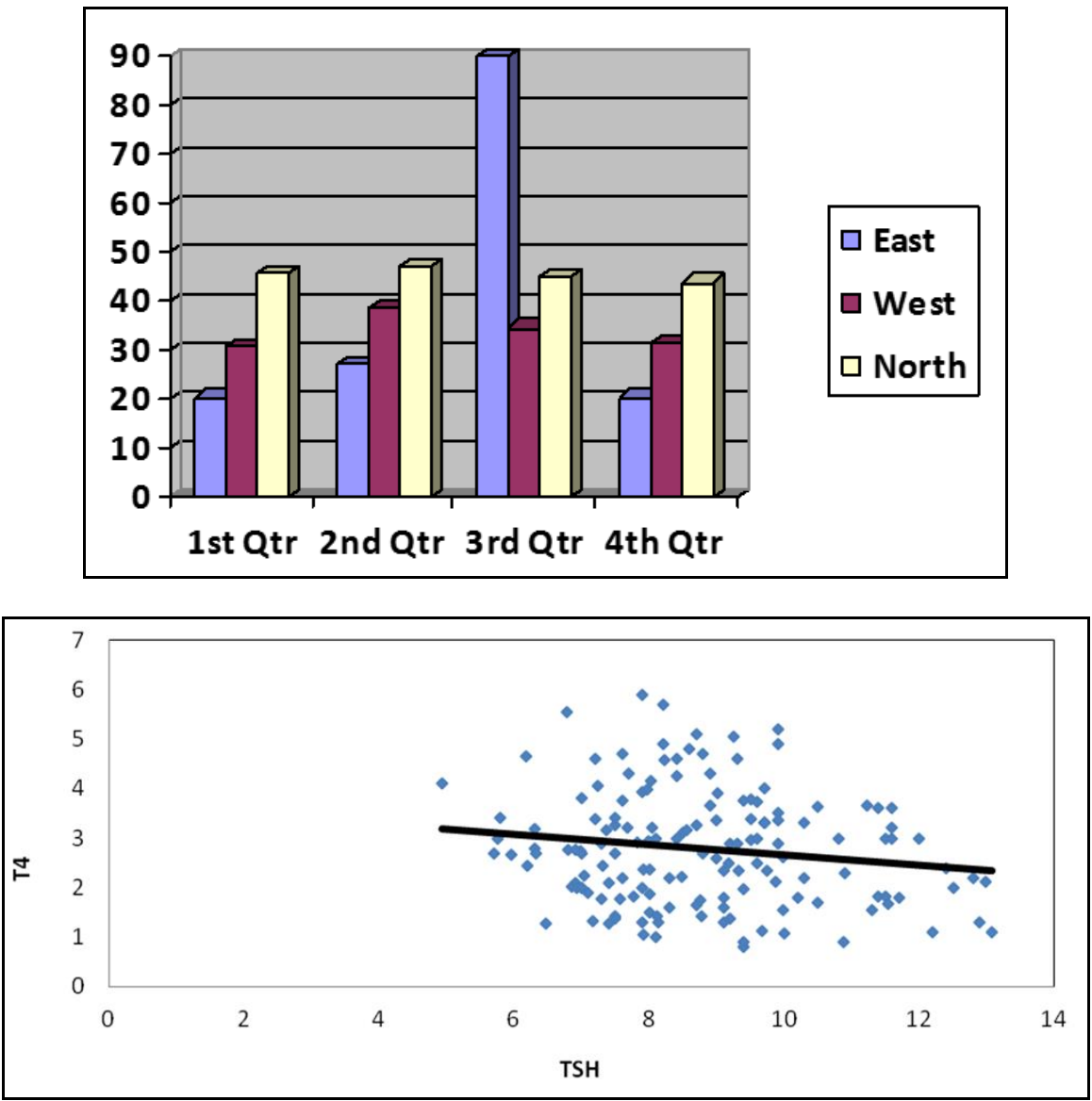

Fig. 2: Scatter plot between T4 and TSH

\section{Discussion}

Our study has established own reference range of T3, T4 and TSH hormone at clinical biochemistry laboratory, GCS Hospital, Ahmedabad, Gujarat. A tertiary care level clinical laboratory should ideally have its own reference range from the population that it caters to which improves the accuracy in diagnosis of disease. Common scenario in hospitals and research laboratories, is to use the manufacturer's ranges for a given clinical laboratory assay system. Many of these assay systems are procured from Europe or the United
States and use reference values based on their populations, which may not be representative of the our population. ${ }^{11-14}$

In conclusion, we have established reference intervals at our laboratory as $0.77-1.69 \mathrm{ng} / \mathrm{ml}, 5.37$ $12.10 \mu \mathrm{g} / \mathrm{dl}$ and $0.50-5.06 \mu \mathrm{IU} / \mathrm{ml}$ for T3, T4 and TSH hormones respectively. This is at variance from the manufacturer value of $0.84-2.02 \mathrm{ng} / \mathrm{ml}, 5.13-14.06$ $\mu \mathrm{g} / \mathrm{dl}$ and $0.27-4.20 \mu \mathrm{IU} / \mathrm{ml}$. 
We would like to suggest the need for establishing a specific reference range for our Indian population in a broader collaborative study in future.

\section{References}

1. M. Alqahatani, W. Tamimi et al. Young adult reference ranges for thyroid function tests on the Centaur immunoassay analyser. Br J Biomed Sci. 2006;63(4):1635.

2. Raman Kumar Marwaha, Nikhil Tandon et al. Reference range of thyroid function (FT3, FT4 and TSH) among Indian adults. Clinical Biochemistry. 46 (2013) 341-345.

3. Bernadette Biondi; The Normal TSH Reference Range: What Has Changed in the Last Decade?. J Clin Endocrinol Metab 2013;98(9):3584-3587. doi:10.1210/jc.2013-2760.

4. Hollowell JG, Staehling NW, Flanders WD, et al. Serum TSH, T4, and thyroid antibodies in the United States population (1988 to 1994): National Health and Nutrition Examination Survey (NHANES III). J Clin Endocrinol Metab. 2002;87:489-499.

5. Solberg HE. International Federation of Clinical Chemistry. International Committee for Standardization in Hematology. Approved recommendations (1986) on the theory of reference values. Part 1 . The concept of reference values. J Clin Chem Clin Biochem 1987;25:337-42.

6. Girgensohn S, Liedtke R, Balzer G, Castor S, Hauser M. Performance of the ACS: Centaur high-capacity, randomaccess immunoassay system. Clin Lab 1997;43:975-83.

7. National Committee for Clinical Laboratory Standards. How to define and determine reference intervals in the clinical laboratory: approved guidelines (NCCLS C28-A). Villanova, Penn: NCCLS, 1995. ISBN 1-56238-269-1.

8. Outliers in statistical data: Barnett V and Lewis T 1994, $3^{\text {rd }}$ edition, (John Wiley \& Sons, Chichester), p.175-6.

9. Dixon WJ. Processing data for outliers. Biometrics. 1953;9:74-89.

10. Campbell MJ, Gardner MJ (1988). Statistics in Medicine: Calculating confidence intervals for some non-parametric analyses, Br Med J (Clin Res Ed). 1988 May 21;296(6634):1454-1456.
11. PetitClerc C, Solberg HE. International Federation of Clinical Chemistry. International Committee for Standardization in Hematology. Approved recommendations on the theory of reference values. Part 2. Selection of individuals for the production of reference values. J Clin Chem Clin Biochem. 1987;25:639-44.

12. Solberg HE, Stasman D. International Federation of Clinical Chemistry. Approved recommendations on the theory of reference values. Part 4. Control of analytical variation in the production, transfer and application of reference values. Eur J Clin Chem Biochem 1991;29:531-5.

13. Solberg HE. International Federation of Clinical Chemistry. Scientific Committee. Clinical Section Expert Panel on Theory of Reference Values and International Committee for Standardization in Hematology. Standing Committee on Reference Values approved recommendations on the theory of reference values. Part 5. Statistical treatment of collected reference values. Determination of reference limits. J Clin Chem Clin Biochem 1987;25:645-56.

14. Dybkaer R, Solberg HE. International Federation of Clinical Chemistry. International Committee for Standardization in Hematology. Approved recommendation on the theory of reference values. Part 6 . Presentation of observed values related to reference values. J Clin Chem Clin Biochem 1987;25:657-62.

How to cite this article: Jadav PM, Pradhan R. Establishment of reference range for thyroid hormones (T3, T4 \& TSH) in adult female population at clinical biochemistry laboratory of GCS Medical College \& Hospital- A descriptive study. Int J Clin Biochem Res. 2018;5(3):449452. 